\title{
Educational leadership and the imperative of including student voices, student interests, and students' lives in the mainstream
}

\author{
LAWRENCE ANGUS
}

Smyth introduces this special issue with the claim that the question of 'how to pursue forms of leadership that listen to and attend to the voices of... young people' is the 'most urgent issue of our times'. Smyth writes passionately about young people, particularly disadvantaged and marginalized young people and their relationship with schools. Of special concern to him in recent times has been the increasing number of such students who are poorly served by schools and are, in effect, pushed out of the institution of schooling by a system that is largely uncaring and remote from their needs and interests.

\section{The hardening of educational policy}

Smyth sees it as no coincidence that widespread neglect of the needs and interests of disadvantaged and marginalized youth has corresponded with the entrenchment in education policy of accountability and compliance measures, particularly high stakes testing. Such measures are intended to control schools, teachers, and students rather than enhance educative possibilities. Concern with measurement and standards in schools, according to Smyth and his colleagues in this special issue, has steadily displaced what had been emerging in the 1960s and 1970s as an ethos of caring and social responsibility in schools. This has now been well and truly replaced by an impersonal ethos of competition and performativity that has little place for attempts to understand and accommodate the everyday lived experiences and cultures of young people. The hardening of the policy regime and of educational attitudes has meant that, instead of schools changing their norms and ways of operating to accommodate the diversity of students, including the least advantaged, both the market arrangements under which schools now operate and the heavy compliance regimes force schools towards an impersonal homogeneity defined by impersonal and remote standards. Students and teachers are now expected to turn themselves into the kinds of people demanded by 
ostensible 'high performing' schools that are concerned with grades and test results and compliance with the managerial norms that now characterize education as an institution.

Some students fare very well in the testing, compliance environment and, despite the bland curriculum, unimaginative pedagogy, and relentless measurement that characterize managerialist schools, are motivated to acquire the grades that will ensure their future educational and life chances. Often, for such young people, the 'decision' to be successful at school and proceed to university is, as Ball et al. (2002: 54) put it, 'a non-decision' because it seems part of a 'normal' and expected social trajectory. But such is often not the case for some other children. Typically, for such young people, the 'decision' to try to be successful at schools has to be an 'active' decision that is much more problematic (Ball et al. 2002), because they and their families lack the social and cultural resources and supports that are generally available to, say, middle class people. This makes the reproduction of disadvantage, for them, much more likely. To make such a decision to comply with the institution of schooling, the young person has to have some personal connection to the school, a stake in what the school is perceived to offer, and a sense of the worthwhileness of the schooling experience. The young person has to decide to comply with the school experience and school staff, rather than reject and resist them. The starting point for facilitating such decision making by young people is likely to be when the school, its teachers, and leaders reach out to such children, move to meet them rather than expecting them to adjust to the entrenched school and teacher paradigms, and attempt to engage them in relevant and interesting school experiences in which they can recognize themselves, their parents, and their neighbours. But because schools have generally become impersonal and hard-hearted, school teachers and managers seem to be doing less of the difficult educational and cultural and political work of trying to engage lessadvantaged young people in the institutional life of schooling. The result is that the students who most need support to become engaged in schooling are now more likely to be disillusioned, ignored, and even denigrated by the school system. Small wonder many of them respond with hostility and rejection of schooling.

Dana Mitra's article describes what seem to be serious and elaborate attempts to involve students in school decision-making and, more pointedly, school reform. The groups of students described by Mitra seem to have managed to get access to the influential leaders in the school, including principals and senior staff, and, according to the author, were prepared to do the hard work of gaining sufficient legitimacy to be included in leading school reforms.

\section{Student participation in reform efforts}

Mitra examines three case studies of the 'positioning' of student groups engaged in 'student voice efforts' and their attempts to be taken seriously in the politics of school reform. Two of the groups were formed within the one school and a third group was formed outside another school but was 
composed of members who were students at the school. The central problematic, therefore, is the efficacy of student voice efforts that operate within the rules (formal and informal) of the official school institution, compared with operating from the basis of a community group concerned with broad youth issues including the issue of student participation in school governance and reform. Mitra's conclusion is that the group with the wider youth constituency formed in the community outside the school was better positioned to form multiple alliances and pressure the school administration for changes based on student rights. The groups that operated within the school had limited resources of power to assert their rights in a political sense but nonetheless were able to cooperate with teachers in addressing studentteacher relationships.

The two schools concerned have precisely the kinds of students Smyth is concerned with, but I learnt very little from the article about how and why the young people were invited into, or demanded to be part of, participation in school reform attempts. It took me several readings to work out the following: The schools were able to receive funding for school reform initiatives through an organization called the Bay Area School Reform Collaborative (BASC). The criteria for funding were not made clear in the article but the funds were substantial —up to $\$ 150$ per student for up to five years. Two of the three case study groups, which had the names 'Student Forum' and 'Pupil-School Collaborative', were located at Whitman High School but, strangely, appear not to have interacted with each other. The groups seem to have been, in effect, school-based clubs that had adult advisors (in one case a teacher, and, in the other, an adult who was hired by the school specifically for this job), who were very influential in their success. Unity of Youth, however, was apparently a group formed from the membership of an un-named community-based organization in the catchment area of Hillside High School.

The level and extent of political participation by the young people, whether or not that participation was managed by the school, seems extraordinary in an educational world in which, according to the other articles in this special issue, such participation rarely occurs and, when it does occur, is typically minimal and/or tokenistic. I would have liked to have learnt from the author about how and why substantial funding was made available for the student projects to the schools concerned; how and why did the schools officially sanction the 'reform efforts'; how did the young people participate in the reform-oriented groups; and what, if anything, was achieved? It seemed to me a brilliant initiative that one school-based group arranged for students to take teachers on tours of the local neighbourhood and introduced the teachers to something of the nature of their community, including areas that most teachers were normally afraid to enter. It seems even more extraordinary that a community youth group had an agenda for action that included 'the development of a Student Unity Centre that would provide students with a range of services in one location, including health services, academic support with tutoring and mentoring, after-school programmes, job placement, an ethnic studies library, and conflict resolution resources'. Wow! This ambitious youth action, with messages of pride in community and school, and profound concepts of community and social 
capital building, is going on in a neighbourhood comprised mainly of 'first-generation immigrants from Latin America and Asia as well as working-class African-Americans'. And the work was supported by a high school that graduates only $18 \%$ of students in a typical year. How were these extraordinary reform efforts generated and what can we learn from them? And what can we learn about inclusive, student-oriented leadership? I still want to know.

As readers of this journal will be aware, Smyth has long been interested in schools that, against the odds as it were, manage to engage their students, keep them in school, and treat them in mature and nonpatronizing ways that connect with their lives and cultures. He has found that, typically, such schools deliberately reject currently dominant 'reform' trajectories and, instead, create space for teachers and students to develop good educational practice, instead of blithely following measurement regimes and artificial, imposed, so-called 'best practice'. He wants leaders to promote the educational professionalism of their colleagues and the inclusion of students rather than following the dictates of managerial control. He wants us to stop and critically examine current so-called 'reforms' and their influence on the politics of education. One of his main themes is that issues of democracy and social justice, not just in education but also in other social spheres, have been displaced by managerialist norms that are linked to the presumed needs of business and industry. This situation has a profoundly narrowing and limiting effect on our dreams and ideals of what education might become. Our conceptualization of the nature and purpose of education is restricted in this climate and policy framework. That is why scholars like Smyth seek to restore 'educational' values and norms to the forefront of educational thinking, educational policy, and educational leadership.

This is not to deny that leadership is always difficult, and always involves tensions and contradictions. Leadership has to be relational-it is a socially constructed relationship between people. In this sense leadership is more of a dialectical process than a fixed thing, and leads to the production and reproduction (and discarding or assertion) of various organizational practices, norms, and structures. In democratic organizations - indeed in any organizations in which there is genuine leadership rather than merely managerial coercion-such organizational shaping is never just a top-down process but is an engaged process involving all organizational players. The dialectical, relational view of leadership as a process incorporates the human agency of all members of the organization. These inevitably interact with each other and with the simultaneously enabling and constraining (enabling in some ways and constraining in others) norms, practices, and structures of the organization. Democratic and transformative leadership takes place in such environments, which are dynamic rather than static, and which themselves are located in complex social and political contexts. Such leadership arises not from coercion and manipulation, but from relational collaborative, participatory processes. Indeed, the importance of the relational nature of schooling generally, and particularly of the student-teacher relationship, is a key theme of several of the articles in this special issue. 


\section{Leaders and followers}

Like Smyth and Fielding, Cook-Sather is also concerned to promote learning and teaching as a collective, relational experience. She writes about pre-service teachers who, as part of a Teaching and Learning Together (TLT) project, are encouraged to explicitly challenge the traditional hierarchy of teacher/leader-student, which, she argues, restricts student-teacher collegiality and promotes impersonal, individualistic education. The TLT project tried to develop in pre-service teachers a sense of 'paradoxical leadership' in which the teacher/leader sometimes follows and sometimes leads. This paradox of simultaneously leading and following is spelt out nicely in the article and is used as a pedagogical tool to assist the pre-service teachers to come to rich understandings of the complexities of leadership and the student-teacher relationship. The pre-service teachers pair with students at a suburban high school (in which the students streamed into 'tracks' that are appallingly labelled 'gifted', 'regular', and 'special education') and engage in email conversations with their student partner each week. The pre-service teachers also get to read transcripts of weekly conversations of the high school participants talking about the experience.

Cook-Sather worries that classroom teachers typically experience 'pressures to satisfy the requirements of federal legislation such as No Child Left Behind as well as national state standards', and that such pressure exacerbates the phenomenon of classrooms being run 'according to individualistic, instrumental, and undemocratic principles'. In her view, such schools and classrooms have become dysfunctional, anti-educational places. Like Fielding, Cook-Sather is concerned that beginning teachers are likely to become inducted into the dominant, managerial teacher paradigm, so she is doing her best to inoculate her student teachers against being dragged uncritically into that paradigm. Through the Teaching and Learning Together (TLT) project, and particularly through trying to get the preservice teachers to 'really listen to student feedback and change based on what students say', Cook-Sather tries to show her student teachers that teaching is more complex than policy documents portray. Her main lesson is that the student-teacher relationship is highly paradoxical. By meeting with, talking with, and talking about their student partners, the pre-service teachers in the project are challenged 'to enact the educational process, not as the one-way transfer of knowledge from teacher to student in preparation for performance on standardized tests, but rather as a mutually informing, dynamic, human relationship within which knowledge and understanding are co-produced by teachers and students'. Cook-Sather is aware of the danger that challenging would-be teachers to confront conventional practices that have been solidified during an era of mechanisms of teacher control and surveillance and high stakes testing might well be counterproductive. It may set them up for professional disillusionment and even peer hostility when they get jobs in schools that are likely to have been drawn into hierarchical and managerial practices. But at least these beginning teachers will have some experience of what is hopefully a genuinely and inclusive educational episode as part of the TLT project. Whether the experience will be so empowering that it will enable them to 'begin the lifelong 
work of resisting the imposition of oppressive, disempowering, and commonly accepted educational practices' remains to be seen.

\section{The moral purpose of educational leadership}

Current policies that Cook-Sather believes are having a damaging effect on education and teachers, and which Smyth is worried about, fit with an overarching social policy framework in which education is largely integrated into economic policy in such a way that education is seen as servant to capital and the 'new economy'. The heavy policy overlay of managerialism and competitiveness weighs heavily on educators, students, and parents and, as Smyth and Fielding argue, replaces any concept of educative leadership with standards and standardization. The blanket overlay leads us, even if unwillingly (Angus 2004), to accept 'dominant' meanings that shape our processes of meaning-making and identity construction as teachers, students, or principals. Under such conditions we are more likely to overlook the key question that scholars of leadership like the late Bill Foster posed for us: How can school leadership foster and support a democratic polity? What does it mean to be an ethical leader? How do we combine the means of administering schools with an awareness of the larger ends of education? What does it mean for a leader to be transformative? (See discussion in Anderson 2004). These are serious questions which, taken together, frame the key educational issue that Smyth has declared is critical for current education; namely, the moral purpose of education and educational leadership to promote in schools as social institutions the core values of social justice, democracy, and equity. Such educational leadership work has become increasingly difficult in recent decades, as scholars such as Shields, Sergiovanni, Bottery, and Starratt, as well as Smyth and Foster have tried to show us. It may be instructive to reflect on what such scholars have been saying recently in relation to the theme of this special issue. For example, as Doyle summarizes the position being put by Thomas Sergiovanni over more than a decade:

\footnotetext{
... leaders must ask questions that focus on equity, questions such as, What is being shared? Why? Who will win and who will lose? Leaders who are democratic facilitate critique that sparks individuals to ask these questions and then evaluate actions against those questions. Democratic leaders facilitate transformation by stimulating critical inquiry in environments where people trust that they will be rewarded for questioning and challenging current visions and practices. (in Doyle 2003: 156)
}

Shields (2004) is under no illusions that such work of educative leaders is tough and becoming tougher. She says:

\footnotetext{
It is little wonder that many believe educational leadership itself is in a crisis... Educational leaders are [also] expected to be transformative, to attend to social justice as well as academic achievement... I propose that transformative leadership, based on dialogue and strong relationships can provide opportunities for all children to learn in school communities that are socially just and deeply democratic. (pp. 109-110)
}

Such a socially critical approach to leadership, and to education more broadly, is necessary to critique current 'realities' and to promote fair and 
equitable, inclusive, truly democratic participation of all young people in education. Shields explains this point in relation to US schooling as follows:

\begin{abstract}
When children feel they belong and find their realities reflected in the curriculum and conversations of schooling, research has demonstrated repeatedly that they are more engaged in learning and that they experience greater school success. The research shows that the benefits extend beyond the specific conversation to increased academic self-concept and increased involvement in school life. Unless all children experience a sense of belonging in our schools, they are being educated in institutions that exclude and marginalize them, that perpetuate inequity and inequality rather than democracy and social justice. (Shields 2004: 122)
\end{abstract}

Yet, as contributors to this special issue make clear, the mind-numbing uniformity of regimes of accountability and testing promote managerialism within a moral vacuum that displaces 'richer, more humane, conceptions of educational management' (Bottery 1999: 300). We can lose touch with the moral obligation of educational leaders to try to 'develop, challenge, and liberate human souls' (Foster 1986: 18) or with what Foster summarizes as the educational leader's professional ethic:

Each administrative decision carries with it a restructuring of a human life; this is why administration at its heart is the resolution of moral dilemmas. (1986:33)

Perhaps Foster's point is made even more strongly by long-term contributor to the educational leadership literature, Robert Starratt, who, reflecting on his own work of advocating leadership over a long period of time, finds himself forced to conclude:

I raise the question of the morality of an educator claiming to 'lead' a school, when what schools do to altogether too many teachers and children is indefensible. (2001: 334)

We know that schools are embedded within power relationships that do not work to the advantage of all children (and not to society as a whole). These sorts of realizations have become increasingly obvious and many educators have reacted to them. As Smyth and his colleagues put it elsewhere:

Schooling is not working for increasing numbers of young people, particularly for people living in disadvantage. But some... schools have found a way of thinking and acting that goes beyond satisfying the individualistic quest for credentials by embracing alternative images of schooling around ideals of community, dialog, social justice and critical literacies. (Smyth et al. 2003: 178)

But many educators have also realized that bringing about changes to the educational relationships that contribute to the disadvantage of identifiable social groups requires us, as educators, to develop 'deeper understandings of the way we are constructing young people' (Furlong 1991: 326). In other words we have to think beyond ourselves and beyond the teachers, students, and parents as individuals whom we know should be getting a better deal from the education system. We must try to understand how education as a social institution systematically acts to disadvantage certain types of people. Then we are obliged, as principled educators, to take the sort of moral stance declared by people like Foster and Starratt and try to do something about it in conjunction with our colleagues. Smyth is trying to do something about it in this issue, and his main point is that education, to be socially responsible, must make a difference in the lives of the most disadvantaged students. $\mathrm{He}$ 
further argues that, to do so, education must be inclusive of 'the lives, experiences, cultures, family backgrounds, aspirations, and hopes of young people'. Such inclusiveness is necessary because student behaviour, as Erickson points out, is a co-production between teachers and students in which the teaching problematic is an interactional phenomenon to which teacher and student both contribute' (Erickson 1987: 337-8; quoted by Smyth). The upshot is that 'schools "work at" failing their students and students "work at" failing to achieve in school' (Erickson 1987: 336; quoted by Smyth). In other words, students are unlikely to make the active choice to try to succeed in school if the school seems like a foreign country in which they are outsiders. And the 'foreignness' of schools for disadvantaged students means that such a choice is not easy to make if they are, as Smyth puts it, 'living in one reality at home, in another reality with peers and then negotiating another reality in school'. School is already tough for a large proportion of young people and they need to be given ways of connecting with the culture and experience of schooling. Smyth again quotes Erickson to summarize this point:

As students grow older and experience repeated failure and negative encounters with teachers, they develop oppositional cultural patterns as a symbol of their disaffiliation with what they experience. (Erickson 1987: 348)

School leadership in such circumstances means being prepared to buck the rules, to challenge the status quo, to put 'relationships at the centre of everything' and to worry more about engaging young people in schooling than managing their behaviour. Education is vital for all young people, which is why Smyth urges all educators to think seriously about the elements of what he calls 'the pedagogically engaged school'.

\section{What counts as 'genuine' participation?}

Fielding is also interested in schools that will engage all young people. $\mathrm{He}$ introduces readers to a framework in which four ideal types (in the Weberian sense) of school are described. Of the four, the main ones that he deals with are schools of 'the high performance learning organization' type and the 'person-centred learning community' type. The former is the kind of school that is likely to be a star performer within the current policy context. It is results-oriented and perceived as being successful, but is, at its core, manipulative of students and essentially totalitarian in the way it produces compliance through techniques of what might be called 'managed participation'. The concept of organizational control through managed participation is by now quite familiar in mainstream management literature. Such forms of control have become very subtle and quite insidious through the promotion of a discourse of corporate culture that leaders are expected to be able to create and assert.

When this mentality is translated into schools, school failure is represented as the responsibility of the schools and individuals, and is related to the adequacy of the product and not to the socio-political, cultural, and economic factors that sociologists have been attempting to unravel for 
decades. That is, as Ball (1997: 327) concludes when referring to notions of 'quality' and 'accountability' within school effectiveness discourse, such terms act as 'relay devices' that link 'government "mentalities" and policies with everyday organizational realities'. The discourses that link market, accountability, and managerialism, to the extent that they become regularized into organizational thinking and practices in schools and their communities, have a profound effect on the nature of education and on the nature of the education profession for teachers and managers.

The organizational focus of 'high performance learning organization' schools in this high stakes context is likely to be on maximizing students' scores, and students themselves are often co-opted into this endeavour. Such cooption seems to be happening in the three schools described in Osberg, Pope, and Galloway's article (this issue), which, at first glance, seems an odd inclusion in this special issue and somewhat irrelevant to Smyth's concern for disengaged adolescents who are virtually forced out of secondary schools. The students at the three schools that are used as case studies (and which are described respectively as being 'one of the highest performing schools in the state', as having 'walkways lined with flowers [that] curve around... grand, old stone buildings', and 'well-manicured soccer fields') would seem to be clearly members of the kinds of social elite that are assumed to be disproportionately well-served by contemporary schooling. Indeed, in introducing the three schools, the authors seem to have chosen their words deliberately to emphasize the social exclusiveness of the schools and their students. But even these 'top students' apparently suffer great stress and anxiety as they struggle to maintain their reputations as the best and the brightest. These students are clearly winners in the competitive world of schooling, but their success comes at a price, which seems to include extremely hard work at mastering the rules of the game of acquiring high marks. The cost seems to be that their sense of academic integrity is threatened by their competitive behaviour and issues of cheating, and they risk disengagement from any joy of learning for the sake of accumulating marks. Some of them seem to be turning into, or perhaps have been forced to become, the kind of students they never wanted to be. This article suggests that competitive education, while it might be tolerated by academically strong students for the sake of their scramble for high marks, may be extremely unsatisfying for them as well as for disadvantaged students.

The trouble is that the kinds of pupil inclusion adopted at the three schools discussed in the paper by Osberg, Pope, and Galloway seem to reek of the manipulative and exploitative mechanisms of phony democracy that Smyth and Fielding, in particular, warn us against. I was forced to consider whether the schools really are ones in which, according to the title, 'students matter' in a genuine sense, or whether these are examples of 'the use of student voice for particular kinds of adult purposes' so that 'the personal is used for the sake of the functional' (Fielding). The case studies are meant to 'highlight student participation in school reform' through describing teams within the schools that participated in 'the Stressed-Out Students (SOS) intervention' that was designed to 'help school leaders effect change in their school cultures, policies, and practices'. The authors state that their article 'looks closely at school reform and the involvement of student leaders 
occupying a sanctioned seat at the table alongside adult decision-makers'. Interestingly, the spokespersons for each of the three teams when they were invited to speak to an audience of other participants in the SOS intervention were a principal, a parent and teacher, and an assistant principal - no students, despite the SOS projects being supposedly student initiatives.

In each of the three cases, students were outnumbered by adults on the teams, which included four students, two students, and one student. Each student was invited by management ('hand-selected', as the authors put it) to join the teams. In reporting the research, the authors refer to only one student at each of the schools, in each case a female who is assumed to speak for other students. Issues considered by the teams included homework, scheduling, establishment of a test calendar, and school honour code. The single student member of one of the teams seemed clearly tokenistic. Her team met every three weeks but the student, Jayne, was only asked to attend 'strategic' meetings at which, it appears, Jayne was under enormous pressure as the only student. Jayne appears defensive when talking about changes attributed to the SOS team but in which she apparently had no input. The same thing happened at one of the other schools, where the student team member quoted was unaware that the team regularly met without the student members. At the third school, which had only two student members on its SOS team, we are told that the principal 'asserted herself as the unofficial leader of the SOS team'.

With disarming frankness, the assistant principal at one SOS school stated that the staff had a problem in deciding 'how we were going to do this [implement decisions made by the SOS team without any student input at all] so people [i.e. students] felt they were involved but that the educational community [i.e. teachers and administrators] would be the ones making the final decisions'. This sounds like the kind of disingenuousness that Fielding talks about in relation to the sham inclusion of students in 'high performance learning organizations'. I thought the authors must have been setting me up for a strong critique of the shallowness and tokenistic nature of student participation in these three schools. I almost fell out of my comfy chair when I read the authors conclusion that 'all three [case study schools] show how schools can treat students as people whose ideas and opinions about educational reform matter'. I suspect that Fielding would regard the cases as examples of managed participation in which the students were manipulated. He would no doubt contrast the SOS schools with his ideal of the 'personcentred learning community' type of school (as opposed to the 'high performance learning organization') in which 'there is a practical insistence, both in daily work and future planning, of an essentially educational interrogative voice confronting the managerial inclinations of contemporary schooling'. The aim is to promote in schools a 'radical collegiality' that is based on 'mutual trust, care, autonomy, and respect'. In such educational communities the leadership has a much higher responsibility than to managerialist, functional imperatives within which student voice is suppressed or denied. It is the duty of school leaders and all teachers to do more than merely invite student voice. There is a moral responsibility for leaders and teachers to invoke student voice-to insist upon, enquire into, try to understand, interrogate, and generate student voice as best they can. The 
important thing is the attitude and belief that students have voices and opinions and wisdom that is to be respected. The aim is to develop 'emancipatory leadership' (Fielding) so that the voices, values, cultures, and actual life circumstances of students are respected, engaged with, and are incorporated into the life of the school in curriculum and teaching practice.

To give Fielding the last word on the importance of genuine student voice:

I am not just talking about the now much-more-widely-held belief that students have some significant insights into the nature of learning that can and should be utilized by all concerned. What I am suggesting goes beyond the reciprocity of technique and topic. It concerns the more profound, more wide-ranging possibilities of teachers learning with and from young people in holistic ways through processes of co-constructed, collaborative work... [I]n particular contexts and circumstances, students might also teach their teachers.

\section{I agree with Fielding.}

\section{References}

Anderson, G. (2004) William Foster's legacy: Learning from the past and reconstructing the future. Educational Administration Quarterly, 40(2), 240-258.

Angus, L. (2004) Globalization and educational change: Bringing about the reshaping and re-norming of practice. Fournal of Education Policy, 19(1), 23-42

Ball, S. J. (1997) Good schools/bad schools: Paradox and fabrication. British fournal of Sociology of Education, 18(3), 317-336.

Ball, S. J., Davies, J., David, M. and Reay, D. (2002) 'Classification' and 'judgement': Social class and the 'cognitive structures' of choice of higher education. British fournal of Sociology of Education, 23(1), 51-72.

Bottery, M. (1999) Global forces, national mediations and the management of educational institutions. Educational Management \& Administration, 27(3), 299-312.

Doyle, L. (2003) Democratic leadership and students with disabilities: Discordant conversations but not incompatible. International fournal on Leadership in Education, 6(2), 137-160.

Erickson, F. (1987) Transformation and school success: The politics and culture of school achievement. Anthropology and Education Quarterly, 18(4), 335-356.

Foster, W. (1986) Paradigms and Promises: New Approaches to Educational Administration (Amherst, NY: Prometheus Books).

Furlong, J. (1991) Disaffected pupils: Reconstructing the sociological perspective. British fournal of Sociology of Education, 12, 293-307.

Shields, C. (2004) Dialogic leadership for social justice: Overcoming pathologies of silence. Educational Administration Quarterly, 40(1), 109-132.

Smyth, J., McInerney, P. and Hattam, R. (2003) Tackling school leaving at its source: A case of reform in the middle years of schooling. British fournal of Sociology of Education, 24(2), 177-193.

Starratt, R. (2001) Democratic leadership in late modernity: An oxymoron or ironic possibility. International fournal of Leadership in Education, 4(4), 333-354. 